The NCB became interested in the Flixborough venture when it was seeking an outlet for its crude benzol (a source of cyclohexane) produced at coke ovens up and down the country. Its opportunity came when Fisons Ltd, the fertiliser manufacturer, withdrew from partnership with DSM in 1971. By December 1972 a new $£ 15$ million extension to the plant was completed, producing caprolactam from cyclohexane; up to that time phenol had been used as a raw material.

The cyclohexane was oxidised to cyclohexanone and the oxime formed by the addition of ammonia and sulphuric acid. Ammonium sulphate used to be a principal by-product of this reactionwhich is why Fisons were involvedbut was later recycled as phosphoric acid. The oxime was finally converted to caprolactam by Beckmann isomerisation.

A third phase of expansion was to have been commissioned later this year but whether that expansion would have used phenol or cyclohexane had not been decided at the time of the explosion. Mr Grainger says that there is now an emotional argument against the cyclohexane technique but hopes that any further decision will be based on rational grounds. Whatever process might be used in the future, there is strong local opposition to rebuilding the site at Flixborough. Comparisons are inevitably drawn in any industrial disaster of this size with the safety of nuclear installations. These have greater safety restrictions placed upon them and in Britain they need the approval of the Nuclear Inspector, whose decision is final. But a chemical plant may be built without consulting anyone except the local planning authority, who usually have little expert opinion to draw on. The Factory Inspectorate has no say in the matter until the plant is erected. At a time when the safety of nuclear power plants is in question, this seems to be a double standard.

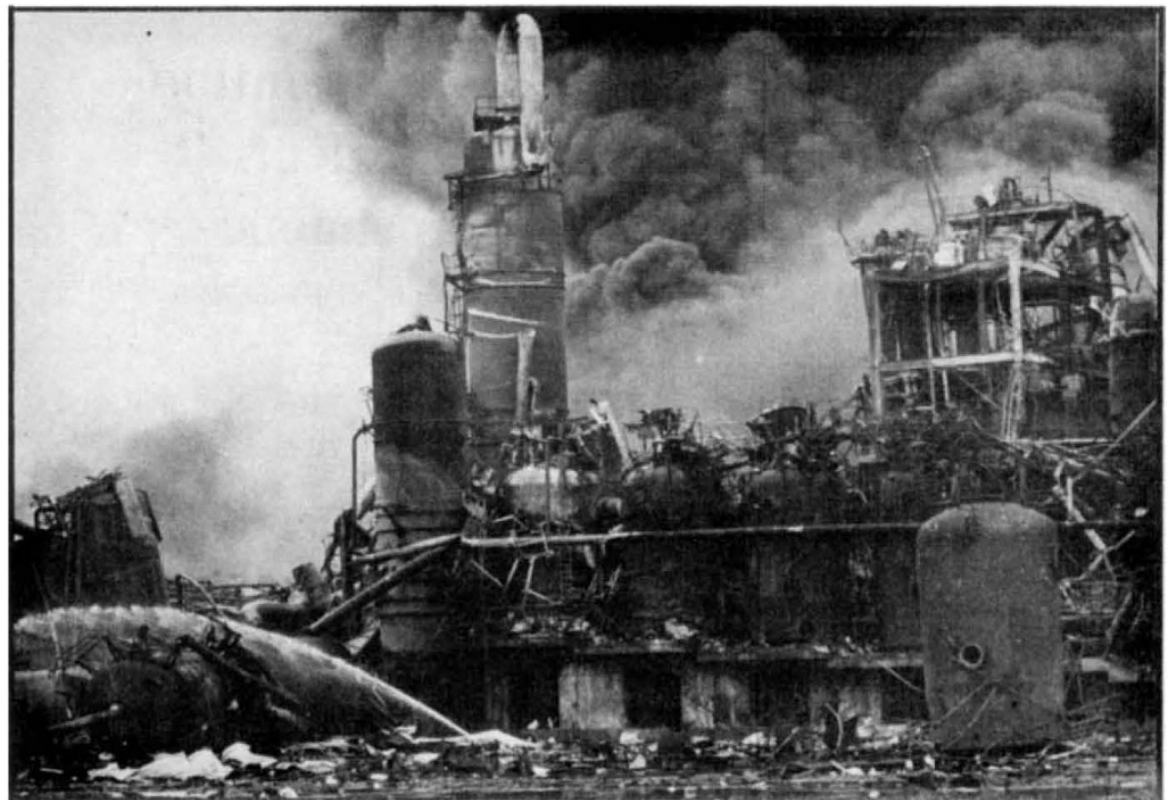

THE oxanone plant at Flixborough, where the leak which caused the fatal blast is thought to have occurred. The picture above shows the cyclohexane containers after the explosion. One tank had been removed from its place for repair, and in the space it had formerly occupied a bridging pipe was

used to connect the remaining tanks (location arrowed in drawing below). Nypro Ltd refused to comment on the suggestion that temporary piping was the source of the leak. They are waiting for the report of the Factory Inspector which will be published later this year.

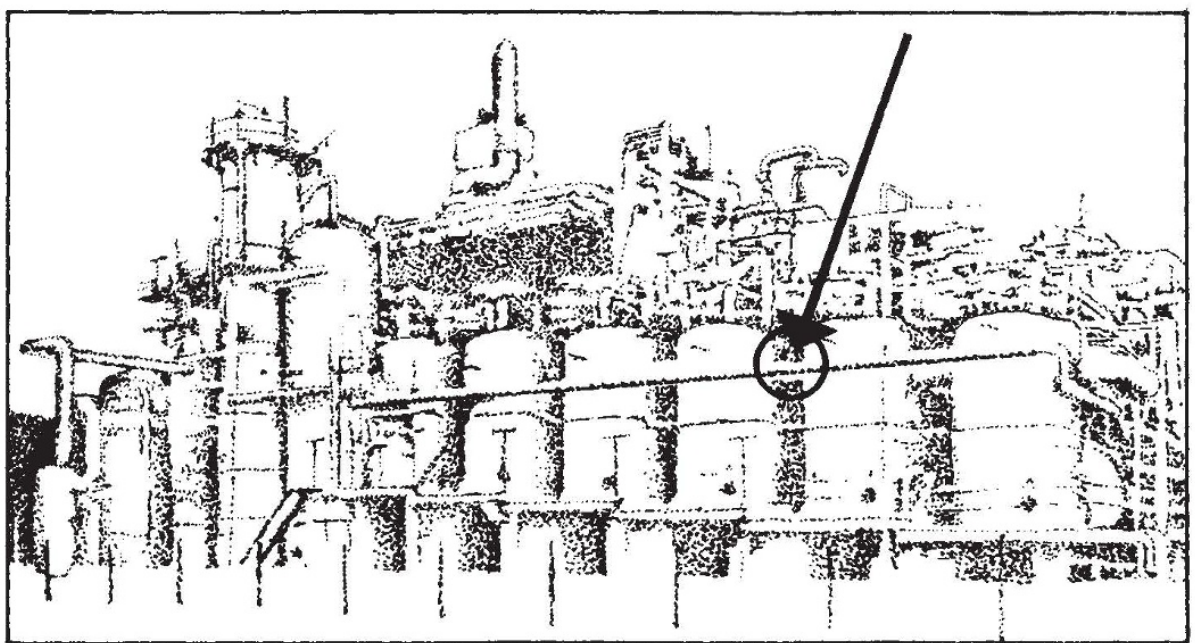

Whatever the precise cause of the Flixborough disaster may turn out to be, Sir Brian Flowers, Rector of Imperial College, London, and Chairman of the Royal Commission on Environmental Pollution has set wheels in motion within Imperial College to find out whether teaching there places sufficient emphasis on reducing technological hazards of all kinds to an absolute minimum. Sir Brian expressed concern in a speech in April that "what is regarded as an acceptable disaster is increasing all the time, whether it is a hijacking or a motorway pile-up It seems strange that increasing acceptance of technological failures should seem to coincide with increasing in-

\section{Teaching for safety in technology}

by Roger Woodham

tolerance of environmental pollution." So the Flixborough disaster was the catalyst but not the cause of the setting up of a working party under Professor A. R. Ubbelohde, Head of the Department of Chemical Engineering and Chemical Technology at Imperial College.

Professor Ubbelohde said last week that the ultimate objective must be to imbue engineers-be they recent graduates or those with industrial experience returning to Imperial College for postexperience courses-with the "concepts of safe design". He also predicted that the monitoring of potential hazards, preferably by two independent methods, will receive much more attention in the future.

Sir Brian says that all too often "clever economic solutions have come before the safe solution which respects life." Modern technology should be fail-safe (so that alterations in any parameter of the system make it safer) but it is not, he said.

The working party has three months to submit a report and it seems unlikely that the document will stay internal to Imperial College for very long. 